\title{
Mellan offentligt och privat, politik och profession - en introduktion
}

\author{
PETER DELLGRAN \& STAFFAN HÖJER
}

\section{Inledning}

Vissa socialpolitiska utvecklingstendenser får av olika skäl stor massmedial och politisk uppmärksamhet medan andra sker mer i det fördolda. De senaste decenniernas mest iögonfallande förändringar av den offentliga tjänsteproduktionen brukar antingen sorteras in under rubriken "resursproblem, nedskärningar och prioriteringar" och/eller förstås inom ramen för den socialpolitiska begreppsfamilj som inrymmer marknadsorientering, decentralisering och privatisering. Med tanke på det faktiska händelseförloppet ter sig inte detta särskilt märkligt men det innebär också en viss risk att vi därigenom fokuserar alltför mycket på vissa fenomen eller binder upp oss till vissa förklaringsmodeller och perspektiv på omvandlingen av den offentliga sektorn.

Temat för detta dubbelnummer är organisering, privatisering och professionalisering. ${ }^{1}$ Underrubriken skulle kunna ha varit

1 Vi vill rikta ett stort tack till CSA (Centralförbundet för Socialt Arbete) vars ekonomiska bidrag möjliggjorde en seminariebehandling av flertalet artiklar som ingår i detta nummer. något i stil med "förbisedda aspekter av förändringar av den svenska välfärdspolitikens utförande, stundtals fjärran från massmedial uppmärksamhet men med principiellt stor betydelse för ansvariga politiker, arbetsledare, professionella yrkesutövare, klienter, patienter, brukare och samhällsmedborgare». Men så pass otympliga rubriker, hur bra de än deklarerar ett innehåll, kan väl ingen vara särskilt förtjust i. Ambitionen är att presentera ett axplock från pågående forskning och därigenom belysa några av de utvecklingstendenser som har präglat de senaste decennierna. Med undantag för Paula Blomqvists artikel, som behandlar privatiseringen inom sjukvården i Tjeckien, Polen och Sverige, är innehållet koncentrerat till socialtjänstens område och inom detta framför allt den verksamhet som rör individ- och familjeomsorgen. Med ytterligare ett undantag - Rebecca Hegars artikel om offentlig och privat social barnavård i USA - handlar det om svenska förhållanden.

Avsikten är således inte att ge en heltäckande beskrivning av sakernas tillstånd eller utveckling inom det välfärdspolitiska området. Att fånga alla aspekter av de för- 
ändringar som har kännetecknat de sociala tjänsteverksamheterna inom vården, skolan och omsorgen under de senaste årtiondena låter sig inte göras på ett par hundra sidor. Inte heller är det möjligt att göra all den forskning om organisations-, professionaliserings- och privatiseringsfrågor som har relevans för det här området rättvisa. Inom vart och ett av dessa teman skulle vi utan vidare kunna fylla ett nummer av Socialvetenskaplig tidskrift. Särskilt de två förstnämnda utgör ett par långlivade forskningstraditioner inom samhällsvetenskapen som har mycket att bidra med för att spegla den vetenskapliga utvecklingen och diskussionen inom det sociala området. Och privatiseringstemat, som har varit aktuellt sedan 1980-talet, skulle även det utan vidare förtjäna ett eget temanummer för att bli någorlunda väl genomlyst.

Den mer avgränsade uppgiften är här att genom empiriska granskningar dels behandla förändringar som inte har fått särskilt stort utrymme i den offentliga debatten, dels belysa undanskymda aspekter av aktuella utvecklingstendenser. Den fortlöpande specialiseringen av den kommunala socialvården eller socionomernas yrkesmässiga karriärer, som ju har mycket stor betydelse för verksamheterna på t.ex. socialkontoren, är ett par exempel på det förstnämnda som diskuteras i flera artiklar. Att professionella yrkesarbetare på välfärdsområdet väljer att lämna sina offentliga anställningar för att istället starta egen privat verksamhet, och att därför inte all privatisering är planerad och policydriven, är ett exempel på det sistnämnda som också det berörs i flera artiklar i detta nummer.

\section{Varför ett temanummer om organisering, privatisering och professionalisering?}

Skälen att samla artiklar runt dessa teman i samma nummer är flera. Organiseringen av den offentliga tjänsteproduktionen är stadd i ständig omvandling och vare sig vi talar om det sociala arbetet, omsorgen, sjukvården eller skolan så har omorganiseringar av verksamheterna varit legio. När det i dessa förändringsprocesser finns aktörer med skilda intressen är det inte mer än rätt att belysa den välfärdsstatliga omvandlingen genom att samtidigt ägna uppmärksamhet åt hur de professionella yrkesgrupperna inte bara påverkas av omvandlingen, utan också hur de själva är med och påverkar densamma.

All professionalisering är i princip en fråga om implementering och därför ett samspel mellan de professionella (och deras yrkesorganisationer) och stat, kommun och andra arbetsgivare. Samtidigt handlar offentlig organisering av tjänsteproducerande verksamheter i mångt och mycket om reglering av professionella gruppers yrkesutövning och framför allt deras handlingsutrymme eller professionella diskretion. Balanseringen mellan politisk styrning och lagstiftning å ena sidan, och kunskapsanvändningen hos de professionella som har fått mandat att utföra vissa samhällsuppgifter å den andra, är en central uppgift för alla organisationer inom det välfärdspolitiska området. Att då studera institutionella strukturer eller implementering av nya organisationsmodeller, program och åtgärder från såväl organisations- som professionsteoretiska perspektiv borde vara fruktbart. Både organisationsteorier och

Peter Dellgran \& Staffan Höjer: Mellan offentligt och privat, politik och profession... 
professionsteorier har dock emellanåt, åtminstone i sina klassiska versioner, kritiserats för att alltför lite ha tagit intryck av varandra.

Moderna professionsteoretiker hävdar att alla yrkesområden är kontinuerligt utsatta för olika typer av förändringar som utmanar den kunskapsdomän som man i varierad grad gjort till sin. Det kan handla om nya organisatoriska former, specialiseringar, privatiseringar eller nya politiska och ideologiska strömningar som påverkar de villkor som omger och sätter gränser för professionernas arbete (Becher 1999). Även om privatisering är ett mångtydigt begrepp som kan ges olika innebörder (se Paula Blomqvist artikel för en bra genomgång) består den vanligaste privatiseringsformen av att delar av produktionen av tjänster övergår i privat regi, med organisatoriska konsekvenser för produktions- och anställningsförhållanden. Likafullt är det inte ovanligt att de organisatoriska konsekvenserna hamnar i bakgrunden i forskning kring privatisering, då fokus snarare brukar vara ekonomi och/eller demokrati.

Vidare finns det, som vi ser det, flera motiv för att relatera privatiseringen till professionsfrågor. Det första, som vi redan varit inne på, handlar om att uppmärksamma de professionellas aktörskap. De så kallade välfärdprofessionerna, som tidigare tillskrevs en viktig roll i välfärdsstatens expansion, är inte bara ett objekt för privatisering och andra omständigheter, de måste rimligtvis också ses som handlande subjekt i den här typen av omvandlingar. De drivkrafter som finns för spontan privatisering (att professionella väljer att starta privata verksamheter) kan i själva verket vara en katalysator för fortsatt privatisering av sociala tjänster. De professionella kommer också att inta olika positioner i den politiska debatten runt privatiseringens brister och förtjänster, vilket vi t.ex. kan se exempel på i den dagsaktuella diskussionen om etableringen av privata sjukhus. Att studera privatiseringen med professionsglasögon möjliggör dessutom fördjupade analyser av konsekvenserna av att de sociala tjänsterna produceras i olika regiformer - inte bara för de professionella utan även för brukare, klienter och patienter.

\section{Organisationer i förändring}

Få samhällsvetenskapliga områden har väl under de senaste decennierna haft en så expansiv och dynamisk utveckling som organisationsforskningen. Staffan Johansson menar i sin artikel i detta temanummer att anledningen till områdets allt starkare position har att göra med att inget akademiskt ämne har fått monopol på området, och att olika discipliner på ett lyckosamt vis korsbefruktat varandra vad gäller teoretisk utveckling och empirisk forskning. En vetenskapsteoretiker skulle säga att organisationer är ett mycket bra exempel (bland flera) på ett gränsobjekt som forskare från olika ämnen delar sitt intresse för, men där varje ämne också har något att hämta i förhållande till sina egna forskningstraditioner.

En annan orsak till organisationsforskningens expansion kan ha att göra med välfärdsstatens finansiella och legitimitetsmässiga kris och talet om effektivitet och demokrati som har följt i dess kölvatten. 
Både effektivitets- och demokratifrågorna riktar ljuset mot välfärdspolitikens institutionella arrangemang och organisering. Decentraliseringen i termer av ökad kommunal frihet, genomslaget av alternativa driftsformer i tjänsteproduktionen, nya styrformer och beställar-/utförarmodeller är alla exempel på fenomen som ökat intresset för att studera socialpolitikens implementering och organisering. Efter organisationsforskningens framsteg har vår bild av organisationer alltmer präglats av att dessa är lika komplexa i sin uppbyggnad som delikat sammanvävda med samhälleliga strukturer. Offentliga organisationer, och den verksamhet som dessa bedriver, är ett resultat av såväl mer instrumentella och interna processer som anpassning till förändringar i omgivningen. Både anpassningen till externa förändringar och interna skeenden sker inom ramen för såväl formella som informella sociala strukturer, historiska arv, kulturella normer och samhälleliga myter. Att fånga denna komplexitet är en stor utmaning för samtidens forskare.

Staffan Johansson konstaterar i temanumrets första artikel, Socialtjänstens organisation som forskningsobjekt, att Sverige anses vara ett av de länder som i högst grad tagit till sig det marknads- och företagsorienterade reformpaket som går under benämningen "New Public Management». Samtidigt finns det förvånande lite forskning om välfärdstatens organisationer och författaren hävdar att många administrativa reformmisstag skulle kunnat undvikas om det funnits en kritisk massa av forskare inom området. Syftet med artikeln är att ge en överblick över kunskapsläget om den svenska socialtjänsten som organisation och att mer specifikt kasta ljus över organisations- och regiformens betydelse för utförandet av socialtjänstverksamheten. I artikeln efterlyses en ökad teoretisk medvetenhet och påpekas att det är angeläget att många disciplinära perspektiv får mötas och befrukta varandra i organisationsstudierna. Dessutom vill Staffan Johansson se ett ökat inslag av komparativa studier mellan olika kommuner, mellan socialtjänsten och andra organisationer inom skolan och sjukvården samt internationellt mellan olika länder och välfärdsregimer. Det sistnämnda aktualiserar ytterligare en fråga, nämligen i vad mån de populära amerikanska teorierna om människovårdande organisationer (Hasenfeld 1992) och gatuplansbyråkratier (Lipsky 1980) är lämpliga verktyg för analyser av svenska förhållanden. En stor skillnad mellan t.ex. Sverige och USA finns i sociallagstiftningen och att det politiska inflytandet i Sverige även finns på den operativa nivån. Svenska vård- och omsorgsorganisationer är dessutom mer transparenta, dvs. öppna för offentlig granskning, jämfört med förhållandena i många andra länder.

Helhetssynen i organisatorisk mening är i praktiken avskaffad och måste betraktas som en historisk parentes konstaterar Åke Bergmark och Tommy Lundström i artikeln En sak i taget? Om specialisering inom socialtjänstens individ- och familjeomsorg. Utifrån en studie av 100 svenska mellanstora kommuner återges en översikt över hur socialtjänstens individ- och familjeomsorg är organiserad. Syftet är att vid sidan av att visa hur specialiseringen inom missbrukarvård, barnavård och försörjningsstöd ser ut också söka olika förklaringar till organisationsstrukturerna. De diskuterar dessutom

Peter Dellgran \& Staffan Höjer: Mellan offentligt och privat, politik och profession... 
specialiseringens tänkbara effekter för socialarbetare och klienter. Förutom den övergripande inriktningen mot allt högre grad av specialisering som gäller inom socialtjänstens samtliga undersökta delområden framträder även andra mönster. Specialiseringen ser annorlunda ut inom försörjningsstödet, där vissa ärenden handhas av lägre utbildad personal jämfört med den sociala barnavården. De senaste årens utveckling har lett till en större organisatorisk heterogenitet där kommunerna väljer olika modeller. De drivkrafter som anges som förklaringar till den ökande specialiseringen under 1980- och 1990-talet och som diskuteras i artikeln är; (1) politiska förändringar, (2) påverkan från professionen, (3) ändrade ekonomiska villkor samt (4) förändrad efterfrågan.

Specialiseringen inom socialtjänstens individ- och familjeomsorg är enligt Åke Bergmark och Tommy Lundström ett exempel på organisatoriska förändringar som har skett mer successivt, och åtminstone delvis i motsats till politiska direktiv. Introduktionen av så kallade beställar-/utförarmodeller i de svenska kommunerna är istället ett exempel på en mer planerad förändring som föregåtts av en omfattande politisk debatt. Stefan Wiklund beskriver i sin artikel Social barnavård $i$ nya former. Om marknadsorientering inom barnavårdsområdet vad som händer när artikulerade politiska ambitioner ska iscensättas i en lokal barnavårdsverksamhet. Frågor som behandlas är hur beställar-/utförarmodellen kan gestalta sig i praktiken och hur personalen upplever en sådan nyordning. Dessutom görs en kartläggning av förekomsten av marknadslösningar i stadsdelarna i Stockholm. Kartläggningen visar att de politiska ambitionerna inte haft särskilt stort genomslag. Med hjälp av ett konkret fall som analyseras i artikeln får vi dessutom ta del av den skepsis, ovilja och osäkerhet som implementeringen av generella organisationsidéer förde med sig. Utan tvekan kan vi i det aktuella fallet prata om marknadsorientering med förhinder med betydande svårigheter att genomföra beställar-/utförarmodellen och konkurrensförfarandet fullt ut, något som det finns erfarenheter av även $i$ andra länder. Stefan Wiklund menar att dessa svårigheter kan ses i ljuset av så kallad nyinstitutionell organisationsteori - introduktionen av marknadsorientering är framför allt en frukt av ett tryck utifrån på socialtjänsten och dess strävan efter legitimitet.

\section{Privatisering med förhinder}

I likhet med marknadsorienteringen mer generellt framstår privatiseringen av den offentliga sektorn både i Sverige och internationellt som ett minst sagt komplext fenomen. Detta gäller såväl den politiska retoriken kring fenomenet som dess konkreta uttryck och utvecklingstendenser. Vad gäller de faktiska uttrycken för det som i varierande grad benämns som privatiseringar framträder en brokig samling av exempel på det socialpolitiska området, såväl på transfererings- som på tjänsteområdet; allt från förändringar av pensionssystemet och andra socialförsäkringar till husläkarsystem, privat sjukvård, skolpeng, friskolor, marknadsorienteringen av allmännyttiga bostadsföretag, kooperativ barnomsorg, äldreomsorg på entreprenad och framväxten av privata företag och stif- 
telser inom missbruks- och ungdomsvården etc.

Debatten har präglats av en hejdlös mix av ståndpunkter och argument för och emot samt en omfattande diskussion om hur man ska förstå relationerna mellan privat och offentligt. Inte minst har svensk och internationell forskning om ideella organisationer och »den tredje sektorn" gett oss en bild av en komplex värld av nätverk och relationer mellan olika aktörer inom det välfärdsstatliga fältet.

Bidragen i detta nummer har inte i någon större utsträckning analyserat den politiska debatten om privatisering. Istället handlar de om privatiseringens uttryck och konsekvenser. Sålunda studeras privatiseringsexempel inom sjukvård, marknadsorientering inom individ- och familjeomsorgen, den sociala barnavården i USA och inom den svenska institutionsvården samt sambanden mellan privatisering och professionalisering.

Litteraturen på privatiseringsområdet innefattar ett växande antal begreppsliga analyser och empiriska studier av varför privatisering har skett inom olika områden (Lundqvist 1997, Granqvist 1997,LeGrand \& Bartlett 1993, Söderström 1999, 2000, Drakeford 2000, Harris 2004). Dessutom har skillnader i privatiseringens omfattning som finns mellan olika länder, socialpolitiska områden eller kommuner uppmärksammats (Trydegård 2001). Vidare återfinns analyser av privatiseringens konsekvenser och effekter på olika nivåer och inom olika välfärdssektorer, t.ex. skolan och sjukvården (Blomqvist \& Rothstein 2000), äldreomsorgen (Svensson \& Edebalk 2001) samt barnavårds- och missbruksinstitutioner (Sallnäs 2000, Bergmark \& Oscarsson 1994). När det gäller effekterna har dock analyserna för de professionellt yrkesverksamma varit mycket begränsade, vilket t.ex. framkommer i Blomqvist och Rothsteins (2000) metanalys av internationell och svensk forskning kring marknadsorienteringen inom skolan respektive sjukvården.

Privatisering har i den politiska debatten ofta framhållits som en lösning på sjukvårdens problem, både i Sverige och i många andra länder. I Östeuropa har privatiseringen av de tidigare sjukvårdssystemen snarast stannat upp under senare år och den politiska entusiasmen för privatiseringar tycks ha svalnat betydligt. Hur denna omsvängning i synen på privatiseringar kan förklaras frågar sig Paula Blomqvist i artikeln Privatisering av sjukvård: politisk lösning eller komplikation? Syftet är att teoretiskt beskriva de idéer som legat till grund för privatiseringssträvandena inom sjukvården och därefter empiriskt belysa försöken att tillämpa dem i tre inbördes ganska olika länder; Sverige, Tjeckien och Polen. Sammanfattningsvis konstaterar hon att erfarenheterna av privatiseringen i de tre länderna visar att balansgången mellan ökad konkurrens och produktivitet å ena sidan och bibehållen offentlig kontroll över resursfördelningen å den andra är mycket svår. Att enbart införa nya rättigheter för privata vårdgivare att etablera sig och konkurrera om kontrakt är inte tillräckligt. Det krävs också en utvecklad statsmakt med kompetens och rutiner för upphandling, resursfördelning och styrning. Tvärtom vad man kan förvänta visar således studien av privatiseringen av sjukvården i Sverige, Polen och Tjeckien att ett villkor för att privatiseringen skall lyckas syns vara en väl

Peter Dellgran \& Staffan Höjer: Mellan offentligt och privat, politik och profession... 
utvecklad offentlig sektor. Slutsatsen går stick i stäv mot dem som hävdar att det är just det faktum att det offentliga inte lyckas svara upp mot de behov eller förväntningar som är själva grunden för att privatisera. Paula Blomqvist visar att privatisering inom sjukvården i de nämnda länderna inte i första hand handlar om att sälja ut produktionsenheter eller tillåta nyetablering av privata företag, utan om att utveckla och anpassa nya offentliga regelsystem. Paradoxalt nog verkar privatiseringen inom vårdens område alltså kräva en utvecklad statsmakt.

Rebecca Hegar från University of Texas at Arlington gör en historisk analys av den sociala barnavården i USA i artikeln Privatization of Child Welfare Services in the U.S.A.: Current Policy in Historical Context. Artikeln, som är skriven på engelska, inleds med en genomgång av olika teoretiska förhållningssätt till privatisering och fortsätter med en diskussion om den sociala barnavården under olika epoker i USA från 1600-talets koloniala period till dagens situation under Bushadministrationen. Artikeln avslutas med en värdebaserad socialpolitisk analys om den sociala barnavården. Även om de privata inslagen är vanligare som helhet inom socialt arbete i USA jämfört med Sverige, avslöjar den historiska genomgången att styrkeförhållandena mellan privat och offentligt har varierat avsevärt. Idag är pendeln på väg mot ökad privatisering och Bush har introducerat en nygammal hållning då han skapat ett „Office of Faith-Based and Community Initiatives». Avsikten är att överlåta mer av de lokala sociala insatserna på trosbaserade rörelser, främst religiösa församlingar. Dessa initia- tiv är ifrågasatta av professionella socialarbetare eftersom man misstänker att inriktningen kommer att innebära en ytterligare deprofessionalisering av det sociala arbetet. Författaren höjer dessutom ett varnande finger emot att allt större vinstinriktade bolag ges för stort inflytande i den sociala barnavården. Erfarenheterna från hälsoområdet ger vid handen att det skulle vara »ett misstag av extraordinära proportioner».

Frågan om privatiseringen och dess förutsättningar inom den svenska socialtjänsten ställdes utan tvekan på sin spets vid mitten av 1990-talet då Socialtjänstlagen ändrades för att skapa förutsättningar för att lägga ut kommunal verksamhet på entreprenad. I artikeln Privatisering av Socialtjänstlagen - rättsliga villkor för att överlämna utredningar inom individ- och familjeomsorgen på entreprenad analyserar Anna Hollander några av de rättsliga problem som privatisering för med sig. Genom ett konkret exempel - Stockholms kommuns projekt "Socialtjänst på entreprenad" som sedermera prövades av Länsrätten i Stockholms län - diskuteras tolknings- och tillämpningsfrågor som aktualiserades. Det är framför allt frågan om hur man skall se på myndighetsutövning som står i fokus. Anna Hollander avslutar sin genomgång med att konstatera att myndighetsutövning handlar både om de funktioner som leder fram till ett beslut och konsekvenserna av själva beslutet. Att dela upp utredningsprocessen inom socialtjänstens individ- och familjeomsorg i olika funktioner försvagar snarare än stärker förutsättningarna för en professionell, rättssäker och demokratisk offentlig beslutsprocess. Samtidigt konstateras att det svårtolkade begreppet 
myndighetsutövning ger utrymme för olika tolkningar av villkoren för privatisering.

\section{Professionalisering och privatisering}

En allt större andel av institutionsvården för barn och ungdomar bedrivs i privat regi. De senaste decenniernas utveckling har inneburit inte bara fler utan också dyrare institutionsplaceringar av unga och vårdkostnaderna tar en allt större andel av individ- och familjeomsorgens budget i kommunerna. Det har uppstått en vårdmarknad med egna spelregler och egna aktörer. I Marie Sallnäs artikel Voordmarknad med svårigheter - om privata aktörer inom institutionsvården för barn och ungdomar ställs frågorna hur, när och varför hemmen har etablerat sig. Dessutom behandlas hur företrädare för de enskilda HVB-hemmen själva ser på sin roll som aktörer på en marknad och vilka strategier man använder i relation till socialtjänsten. Också frågan om vårdavgifter och hur HVB-företrädarna ser på pengarnas roll i verksamheten belyses. Artikeln baseras på en empirisk studie av ett slumpmässigt urval av privata och stiftelsedrivna HVB för barn och ungdomar. Artikelförfattaren menar att det trots regler om tillståndsgivning och tillsyn ställs låga krav för att få starta privata institutioner. Socialtjänsten saknar grundläggande information om den tjänst de betalar mycket varierande priser för och de som är direkt berörda, placerade barn/ungdomar och deras familjer, är sällan med i själva köp/säljprocessen. Det är anmärkningsvärda skillnader i de avgifter hemmen sätter på sina tjänster.
Den största enskilda variabel som påverkar priset är personaltäthet. Annat som påverkar är HVB-bolagens storlek (större bolag = högre pris) och avståndet till institutionen. Placeringar utanför hemlänet är dyrare. Däremot har personalens utbildningsnivå ingen betydelse för vårdavgiftens storlek. Avslutningsvis konstaterar Marie Sallnäs att den vårdmarknad som upprättats inom institutionsvården är behäftad med uppenbara svårigheter och begränsningar.

I den avslutande artikeln - Rörelser $i$ tiden. Professionalisering och privatisering $i$ socialt arbete - är vårt syfte för det första att beskriva och problematisera socionomernas professionalisering och karriärvägar i förhållande till de skilda förutsättningar som råder inom olika arbetsområden (vad gäller vidareutbildning, status, lönenivåer, autonomi etc.). För det andra är syftet att undersöka socionomer med egen privat verksamhet, bland annat genom att jämföra dessa i professionaliseringshänseende med offentliganställda socionomer. En fråga som diskuteras är i vilken utsträckning drivkrafterna bakom privatisering kan ses som individuella professionaliseringsstrategier (i strävan efter professionell autonomi och status) och/eller en reaktion på upplevda försämringar i den offentliga sektorn. Av artikeln att döma - som bygger på en enkätstudie med 1000 svarande socionomer - verkar det finnas ett reellt inslag av båda dessa fenomen.

Inom professionsforskningen hävdas ofta att just strävan efter professionell diskretion i yrkesutövningen i princip är den primära drivkraften i all professionalisering, oavsett om det handlar om kollektiv eller individuell nivå. Den obalanserade profes-

Peter Dellgran \& Staffan Höjer: Mellan offentligt och privat, politik och profession... 
sionaliseringen i termer av stratifierade arbetsvillkor, och de tydliga tendenserna till att många socialarbetare med hjälp av t.ex. vidareutbildning förflyttar sig till områden med mer attraktiva villkor som framkommer i artikeln, har inte minst stor betydelse för landets socialkontor. Det finns en yrkesmässig rörelse från vissa områden med stora inslag av kontroll och myndighetsutövning till områden där kontakterna med klienterna är färre och bygger på frivillighet (terapi och rådgivning), eller där det handlar om arbete med andra professionella snarare än klienter (handledning, undervisning, forskning). För socialkontoren innebär detta stora utmaningar och krav på att utveckla sina organisationer och verksamheter för att behålla kompetent personal och stävja en hög personalomsättning, kontinuitetsproblem osv.

Hur ser då relationen mellan privatisering och professionalisering egentligen ut? I Marie Sallnäs artikel framgår att SoLs genomförande 1982 innebar att privata vårdgivare numer utför de flesta vård- och behandlingsinsatserna inom institutionsvårdens ram. De som inom den sociala barnavården utför det svåraste arbetet, att bedriva behandling och vård med mycket utsatta barn, har samtidigt den lägsta utbildningsnivån. Här kan man med rätta hävda att privatisering riskerar att leda till deprofessionalisering. När å andra sidan sökarljuset sätts på socionomerna själva framträder en delvis motsatt bild. När de socionomer som i Peter Dellgrans och Staffan Höjers artikel har längst utbildning och som skaffat sig unika kompetenser som passar bra i de högst rankade interna statusområdena skall välja karriärväg, väljer många just att starta eget. Privatisering framstår på det viset som en individuell professionaliseringsstrategi.

Trots att detta temanummer uppehåller sig mest kring socialvård och sjukvård kan det som behandlas ses som illustrationer till centrala och mer allmängiltiga frågeställningar kring dynamiken mellan offentligt och privat eller mellan politik och profession. Oavsett graden av uppmärksamhet är förändringar av den offentliga tjänsteproduktionen betingade av ett komplicerat samspel mellan yttre och inre faktorer, men också mellan kortsiktiga, periodspecifika och mer långsiktiga, strukturella faktorer. Olika aktörers intressen, överväganden och strategier för att bemästra strukturella och resursmässiga villkor påverkar utformningen av de offentliga tjänsterna. Detta gäller alldeles oavsett om vårt intresse riktar sig mot barnomsorgen, äldreomsorgen, sjukvården, grundskolan, kriminalvården eller vården av missbrukare.

Samtidigt är det vår mening att såväl drivkrafterna bakom som förändringarnas karaktär och socialpolitiska konsekvenser också måste studeras i sin rätta kontext. Förståelsen av utvecklingsdynamik måste med andra ord relateras till de specifika politiska, ekonomiska, lagstiftningsmässiga och professionella villkor som präglar olika verksamhetsområden. Vi måste mer än tidigare, och mer än vad vi lyckas med i detta nummer, jämföra organisatorisk förändring och dess samspel med professionalisering mellan olika tjänsteområden.

Vår intention har varit att ge en mer 
komplex bild av aktuella fenomen som kan nå bortom de av ideologi och retorik så stängda positioner som stundtals dominerar den offentliga debatten. Allt är således inte alltid som det synes vara och andra tolkningar är möjliga - se där vår devis för detta nummer?

\section{Referenser}

Becher, T. (1999) Professional Practices. Commitment \& Capability in a Changing Environment. New Brunswick: Transaction Publishers.

Bergmark, A. \& Oscarsson, L. (1994) „Från producenternas paradis till marknadens retorik. Den socialtjänstbaserade missbrukarvården under 1980 och 1990-talet", i Pettersson U. (red.) Socialtjänstens klientarbete. Från vision till marknad? Lund: Studentlitteratur.

Blomqvist, P. \& Rothstein, B. (2000) Välfärdsstatens nya ansikte. Demokrati och marknadsreformer inom den offentliga sektorn. Stockholm: Agora.

Drakeford, M. (2000) Privatisation and Social Policy. Harlow: Longman.

Granqvist, N. (1997) Privatisering i princip och praktik. Åbo: Åbos Akademis Förlag.

Harris, J. (2004) The Social Work Business. London: Routledge.

Hasenfeld, Y. (1992) Human Services as Complex Organizations. New York: Sage.

LeGrand, J. \& Bartlett, W. (1993) Qusi-Markets and Social Policy. London: MacMillian Press.
Lipsky, M. (1980) Street-level Bureaucracy. New York: Sage.

Lundqvist, L. (1997) "Privatisering - varför och varför inte?", i Rothstein B. (red.) Politik som organisation. Stockholm: SNS Förlag.

Sallnäs, M. (2000) Barnavårdens institutioner - framväxt, ideologi och struktur. Stockholm: Socialhögskolan, Stockholms universitet.

Svensson, M. \& Edebalk, P-G. (2001) 90-talets anbudskonkurrens $i$ äldreomsorgen - några utvecklingstendenser. Lund: Institutet för hälsooch sjukvårdsekonomi.

Söderström, L. m.fl. (1999) Från dagis till servicehus - välfärdspolitik i livets olika skeden. Stockholm: SNS Förlag.

Söderström, L. m.fl. (2000) Privatiseringens gränser. Perspektiv på välfärdspolitiken. Stockholm: SNSFörlag.

Trydegård, G. (2001) „Välfärdstjänster till salu privatisering och alternativa driftformer under 1990-talet», i SOU 2001:52 Välfärdstjänster i omvandling.

Peter Dellgran \& Staffan Höjer: Mellan offentligt och privat, politik och profession... 